\title{
珙桐种质资源保存样本策略的研究
}

\author{
宋从文 ${ }^{1,2}$ 包满珠 1 \\ （1 华中农业大学,武汉 430070）（2 湖北省林业科学研究院,武汉 430079）
}

\begin{abstract}
摘 要 珙桐 (Davidia involucrata) 是我国特有的共桐科单型属植物, 起源古老, 是第三纪热带植物区系的子遗种, 被 列为国家一级保护植物。利用 RAPD 技术, 通过 11 个多态引物对 5 个天然珙桐种群的遗传多样性、种群内和种群 间的遗传变异进行了研究。结果表明: 珙桐天然种群具有丰富的遗传多样性, 但群体间的差异明显, $26 \%$ 的遗传变 异存在于群体间。研究将珙桐划分为东南部和西北部两大种源区。通过对珙桐群体间及群体内的聚类分析, 结合 遗传标记的捕获曲线研究提出了珙桐种质资源保存的样本策略。原地保存可以选择甘肃文县、四川峨眉山和贵州 梵净山 3 个种群作为保存对象, 每个群体保存面积 $3 \mathrm{hm}^{2}$ 以上; 异地保存应抽取甘肃文县、四川峨眉山、湖北神农 架、贵州梵净山等 4 个群体, 每个群体抽样 30 个以上个体, 株间最小间距 $30 \mathrm{~m}$ 以上, 共计保存 150 个个体, 分别在 东南部和西北部建立一个异地保存点。
\end{abstract}

关键词 珙桐 遗传多样性 种质资源 样本策略

\section{SAMPLING STRATEGY FOR PRESERVATION OF GERM PLASM FROM DAVIDIA INVOLUCRATA}

\author{
SONG Cong-Wen ${ }^{1,2}$ and BAO Man-Zhu ${ }^{1}$ \\ (1 Huazhong Agricultural University, Wuhan 430070, China) (2 Hubei Academy of Forestry, Wuhan 430079, China)
}

\begin{abstract}
Davidia involucrata is a monotypic genus that is a relict from the tropical flora of the Tertiary Period. As a plant endemic to China, it is classified as a first-grade state protection plant. An analysis on genetic diversity and genetic variation within and among populations from five natural populations of $D$. involucrata was conducted using RAPD marker based on 11 polymorphic random primers. The results showed that populations of $D$. involucrata had rich genetic diversity, but those significant differences among populations accounted for $26 \%$ of the genetic variation. Two large provenance plots in the southeast and northwest were established for the study. Based on cluster analysis of genetic diversity of populations of $D$. involucrata and curve analysis of the genetic markers, we put forward a sampling strategy for the preservation of germplasm of $D$. involucra$t a$. For on-site preservation, three populations should be selected for each of the following areas: Wenxian County in Gansu Province, Emeishan in Shichuan Province and Fanjingshan in Guizhou Province. Each population to be preserved should occupy a minimum $3 \mathrm{hm}^{2}$. Off-site preservation should sample a minimum of 30 individuals from each of the following populations: Wenxian County, Emeishan and Shennongjia (in Hubei Province) and Fanjingshan for a total of 150 individuals. Individuals should be planted at a minimum space of $30 \mathrm{~m}$. Also, we suggest that two off-site preservation areas should be established: one in the southeast and one in the northwest regions of China.
\end{abstract}

Key words Davidia involucrata, Genetic diversity, Germplasm, Sampling strategy, Conservation

林木种质资源是地球上保存最完整, 最重要的 复合生态系统的基础资源, 是生物多样性、以及遗传 多样性的基础, 林木种质资源的保存, 对于保护树种 的多样性, 林木遗传的多样性, 为林木良种工程提供 育种素材及其它科学研究和开发利用等方面都具有 极其重要的意义(顾万春等, 1998)。

珙桐 (Davidia involucrata) 系我国特有的珙桐科
单型属植物, 其起源古老, 是第三纪古热带植物区系 的子遗种, 1896 年由法国人 David JPA 首次发现, 被 列为国家一级保护珍稀濒危植物 (傅立国, 1992), 也 是世界著名的子遗活化石观赏木本花卉植物。仅分 布在甘肃东南部的文县、陕西西南部的安康地区、湖 北的神农架及恩施各县市、湖南的武陵山区、贵州的 梵净山、四川的西南部及云南北部共 7 省 40 多个县 
市, 分布的纬度范围为 $23^{\circ} 25^{\prime} \sim 33^{\circ} 38^{\prime} \mathrm{N}$, 经度范围为 $99^{\circ} 05^{\prime} \sim 111^{\circ} 18^{\prime} \mathrm{E}$, 呈星散状分布, 现有的原生群落 面积十分有限, 仅4 $500 \mathrm{hm}^{2}$ (张清华等, 2000)。

本文利用 RAPD 标记研究珙桐的遗传多样性, 种群间的遗传分化和种群内的遗传结构, 从而提出 了珙桐种质资源保存的样本策略。

\section{1 材料和方法}

\section{1 试验材料}

根据珙桐的分布特点, 在甘肃文县、湖北神农 架、湖北宣恩、四川峨眉山、贵州梵净山 5 个地方, 选 择具有连续分布特征的天然林分作为研究对象群 体,在全林分随机抽取 $30 \sim 50$ 株珙桐树 (每两珙桐 株间距不少于 $50 \mathrm{~m}$ ), 分别单株采集叶片。另外, 在 湖北宣恩七姊妹山选择 $50 \mathrm{~m} \times 100 \mathrm{~m}$ 的一块珙桐样 地, 胸径 $6 \mathrm{~cm}$ 以上珙桐植株全部分单株采集叶片, 并标注每一单株位置。采集的叶片置于加入了足量 干燥剂的塑料袋中密封, 带回实验室后置于 $-20{ }^{\circ} \mathrm{C}$ 的冰箱中保存供试。

\section{2 实验方法}

1)DNA 提取 5 个群体一个样地共 240 份样品
（湖北宣恩 40 份、四川峨眉山 41 份、贵州梵净山 37 份、湖北神农架 30 份、甘肃文县 38 份、样地样品 54 份)采用 CTAB 法提取 DNA (Doyle \& Doyle, 1987)。 然后, 测定 DNA 的浓度和纯度, 通过琼脂糖电泳检 查 DNA 的完整性, $-20{ }^{\circ} \mathrm{C}$ 保存备用。

2)引物篮选 随机引物采用 Operon 公司引物 系列 A、B、C、D 共 80 个引物, 经初篮和复篮篮选出 能产生多态性、清晰明亮的谱带且重复性强的 11 个 引物, 对所有样品 DNA 进行扩增。各引物名称、序 列及检测带数见表 1 。

3)RAPD 扩增及产物分离 RAPD 扩增反应条 件: $94{ }^{\circ} \mathrm{C}$ 预变性 $3 \mathrm{~min}$; 然后进入 40 个循环, 每个循 环 $94{ }^{\circ} \mathrm{C}$ 变性 $1 \mathrm{~min}, 45{ }^{\circ} \mathrm{C}$ 退火 $1 \mathrm{~min}, 72{ }^{\circ} \mathrm{C}$ 延伸 2 $\min$; 循环完成后于 $72{ }^{\circ} \mathrm{C}$ 延伸 $7 \mathrm{~min}$, 最后于 $4{ }^{\circ} \mathrm{C}$ 保 存。反应采用 $20 \mu \mathrm{l}$ 体系: $\mathrm{H}_{2} \mathrm{O} 11.6 \mu \mathrm{l}, 10 \times$ Buffer $2 \mu \mathrm{l}\left(100 \mathrm{mmol} \cdot \mathrm{L}^{-1} \mathrm{pH} 8.3 \mathrm{Tris}-\mathrm{Hcl}, 500 \mathrm{mmol} \cdot \mathrm{L}^{-1}\right.$ Kcl, $0.01 \%$ Gelatin ), $2 \mathrm{mmol} \cdot \mathrm{L}^{-1} \operatorname{Mgcl}_{2} 0.8 \mu \mathrm{l}, 0.2$ $\mathrm{mmol} \cdot \mathrm{L}^{-1} \mathrm{dNTP} 0.4 \mu \mathrm{l}, 0.4 \mu \mathrm{mol} \cdot \mathrm{L}^{-1}$ Primer $2 \mu \mathrm{l}, 1$ uTaq $0.2 \mu \mathrm{l}, 30 \mathrm{ug} \cdot \mu \mathrm{l}^{-1}$ DNA $3 \mu \mathrm{l}$ 。扩增产物在 $1 \%$ 含溴化乙锭的琼脂糖凝胶中电泳分离, 最后在紫外 灯下用拍照记录结果(图 1)。

表 111 个随机引物序列及扩增的总带数

Table 1 Sequence and number of total amplification bands in Davidia involucrata by 11 random primers

\begin{tabular}{ccc||ccc}
\hline 引物 & 引物序列 $\left(5^{\prime}-3^{\prime}\right)$ & 总带数 & 引物 & 引物序列 $\left(5^{\prime}-3^{\prime}\right)$ & 总带数 \\
Primer & Sequence $\left(5^{\prime}-3^{\prime}\right)$ & Total bands & Primer & Sequence $\left(5^{\prime}-3^{\prime}\right)$ & Total bands \\
\hline OPA03 & AGTCAGCCAC & 12 & OPB05 & TGCTCCCTTC & 12 \\
OPA11 & CAATCGCCGT & 7 & OPB06 & TGCTCTGCCC & 7 \\
OPA13 & CAGCACCCAC & 7 & OPB11 & GTAGACCCGT & 8 \\
OPB01 & GTTTCGCTCC & 4 & OPB17 & AGGGAACGAG & 12 \\
OPB03 & CATCCCCCTG & 7 & OPB18 & CCACAGCAGT & T8 \\
OPB04 & GGACTGGAGT & 11 & Total & 11 & 98 \\
\hline
\end{tabular}

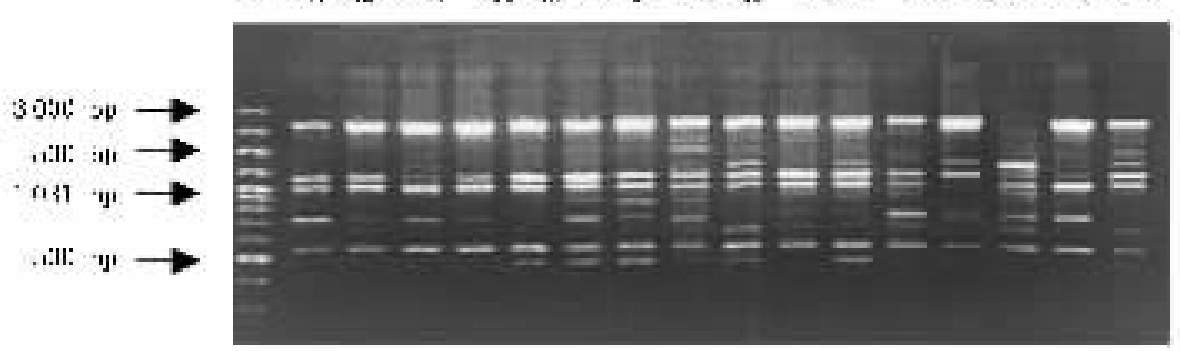

图 1 引物 OPB05 的 RAPD 扩增产物在部分珙桐地理种群样品中的分离

Fig. 1 Segregation of RAPD bands amplified with Primer OPB05 in some provenance samples of Davidia involucrata 


\section{3 数据处理}

RAPD 谱带按 1/0 标记, 利用 POPGENE 软件 Version 1.31 (Yeh \& Yang, 1997)进行数据分析。分 别计算衡量种群遗传变异的多态百分率 (Proqortion of polymorphic loci)、Nei's 基因多样度 (Gene diversity) (Nei，1978）, 以度量珙桐各地理种群的遗传变异。 采用 $F$-统计量分析种群的基因多样性,估算基因分 化系数, 基于地理种群间 Nei (1978)无偏遗传距离 (Unbiased genetic distance) 的估算, 用非加权成组配 对法 (UPGMA) 对 5 个地理种群进行聚类分析, 构建 聚类树状图, 以研究确定珙桐种群间的遗传分化。 对样地样品分别计算两两间的类似度后, 用 UPGMA 法进行聚类分析, 以分析其遗传结构。

\section{2 结果分析}

\section{1 遗传多样性分析}

用 11 个随机引物对 5 个天然珙桐种群共 186 个样品的基因组 DNA 进行了 RAPD 分析, 每个引物 检测到的位点数在 4 12 之间, 共检测到 98 个可重 复的位点。平均每个引物检测到的位点为 8.91 个。

多态位点比率及 Nei's 基因多样度 (表 2) 是检 验种群内遗传多样性的常用指标。从表 2 可见, 珙 桐各种群的多态百分率很高, 平均达到 $75.84 \%$, 不 同种群间多态百分率差异较大, 最高的是四川峨眉 山种群, 高达 $85.15 \%$, 其次是贵州梵净山种群、湖
北神农架种群, 再次为甘肃文县种群, 最低为湖北宣 恩种群, 只有 $64.36 \%$ 。从 Nei's 基因多样度来看, 珙桐种群具有较为丰富的遗传多样性, 其种群平均 值为 0.247 , 高于一般针阔叶树种 0.206 的估算值 （葛颂等,1997）。然而种群间基因多样度相差巨大, 多数种群的遗传多样性丰富, 以贵州梵净山种群、湖 北神农架种群和四川峨眉山种群遗传变异水平最 高, 分别达到 $0.2795 、 0.2774$ 和 0.2600 ; 湖北宣恩 种群内的遗传变异水平较低, 只有 0.1989 。

\section{2 遗传分化分析}

1) 基因分化系数估算结果 (表 3) 显示, 珙桐群 体间的遗传分化达到 $26 \%$ 。珙桐有 $26 \%$ 左右的遗 传变异存在于种群间, 而 $74 \%$ 左右的遗传多样性存 在于种群内, 基因流 $\mathrm{Nm}$ 只有 1.4239 , 这一估算值 近似于我国濒危植物马补木 (Liriodendron chinense) 的研究结果(李建民等, 2002)。

2) Nei's 遗传距离及 UPGMA 聚类分析 表 4 给出了珙桐 5 个种群间的遗传同一性和 Nei's 遗传 距离, 并据此使用 UPGMA 聚类法得出了图 2 所示的 聚类树形图。图 2 聚类树形图显示, 可以很好地按 地理区域将珙桐划分为两个种源区, 第一个种源区 是东南种源区, 第二个种源区是西北种源区。从珙 桐种群间的遗传距离来看, 最大遗传距离存在于湖 北宣恩与甘肃文县之间, 最小遗传距离在湖北神农 架与贵州梵净山之间。

表 25 个珙桐地理种群的多态百分率和 Nei' $s$ 基因多样度

Table 2 Proportion of polymorphic loci and Nei's gene diversity of 5 populations in Davidia involucrata

\begin{tabular}{ccc}
\hline $\begin{array}{c}\text { 地理种群 } \\
\text { Geographic population }\end{array}$ & $\begin{array}{c}\text { 多态百分率 } \\
\text { Proportion of polymorphic loci( \%) }\end{array}$ & $\begin{array}{c}\text { Nei's s 基因多样度 } \\
\text { Nei's gene diversity }\end{array}$ \\
\hline 湖北宣恩 Xuanen, Hubei (XE) & 64.36 & 0.1989 \\
四川峨眉山 Emeishan, Sichuan (EMS) & 85.15 & 0.2600 \\
贵州梵净山 Fanjingshan, Guzhou (FJS) & 80.20 & 0.2795 \\
湖北神农架 Shennongjia, Hubei (SNJ) & 79.21 & 0.2774 \\
甘肃文县 Wenxian, Gansu（WX） & 70.30 & 0.2223 \\
平均 Average & 75.84 & 0.2476 \\
\hline
\end{tabular}

表 3 珙桐地理种群的遗传分化系数

Table 3 Coefficient of genetic differentiation for geographic populations of Davindia involucrata

\begin{tabular}{|c|c|c|c|c|c|}
\hline $\begin{array}{c}\text { 树种 } \\
\text { Species }\end{array}$ & $\begin{array}{c}\text { 总的种群基因 } \\
\text { 多样性 }\left(H_{T}\right) \\
\text { Total gene diversity }\end{array}$ & $\begin{array}{l}\text { 种群内基因 } \\
\text { 多样性 }\left(H_{s}\right) \\
\text { Gene diversity }\end{array}$ & $\begin{array}{c}\text { 种群间基因多样性 }\left(D_{s t}\right) \\
\text { Gene diversity } \\
\text { within populations }\end{array}$ & $\begin{array}{l}\text { 基因分化系数 }\left(G_{s t}\right) \\
\text { Gene differentiation } \\
\text { between populations }\end{array}$ & $\begin{array}{l}\text { 基因流 }(\mathrm{Nm}) \\
\text { Estimata of gene } \\
\text { flow from Gst }\end{array}$ \\
\hline 珙桐 Davidia involucrata & 0.3345 & 0.2476 & 0.0869 & 0.2599 & 1.4239 \\
\hline 马褂木 Liriodendron chinense ${ }^{1)}$ & 0.3911 & 0.2568 & 0.1343 & 0.3434 & \\
\hline
\end{tabular}

1)引自李建民等(2002) Cited from Li et al.（2002） 
表 4 珙桐 5 个地理种群 Nei' $\mathbf{s}$ 遗传同一性(对角线以上)与遗传距离

Table 4 Nei's genetic identity (above diagonal) and genetic distance of five populations in Davidia involucrata

\begin{tabular}{lccccc}
\hline \multicolumn{1}{c}{ 地理种群 Population } & 1 & 2 & 3 & 4 & 0.8878 \\
\hline 湖北宣恩 Xuanen, Hubei (XE) & & 0.8637 & 0.8781 & 0.8141 \\
四川峨眉山 Emeishan, Sichuan (EMS) & 0.1466 & & 0.8580 & 0.8458 & 0.8577 \\
贵州梵净山 Fanjingshan, Guzhou (FJS) & 0.1299 & 0.1531 & & 0.9321 & 0.8285 \\
湖北神农架 Shennongiia, Hubei (SNJ) & 0.1190 & 0.1675 & 0.0703 & 0.1764 \\
甘肃文县 Wenxian, Gansu (WX) & 0.2057 & 0.1535 & 0.1881 & \\
\hline
\end{tabular}

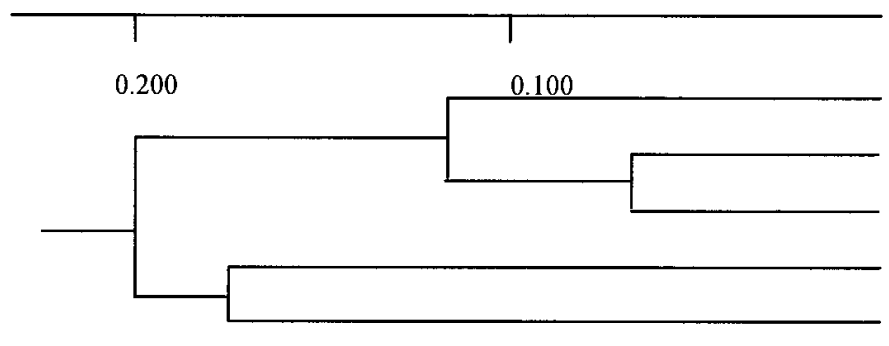

透传距离 Genetic distance

$\mathrm{XE}$

SNJ

FJS

EMS

WX

图 25 个地理种源 UPGMA 聚类法得出的树状图

Fig. 2 Dendrogram showing Nei's genetic distance among 5 populations using UPGMA cluster analysis XE、SNJ、FJS、EMS、WX: 同表 2 See Table 2

\section{3 聚类分析}

由湖北宣恩七姊妹山 $50 \mathrm{~m} \times 100 \mathrm{~m}$ 样地的 54 株珙 桐的 RAPD 分子标记计算两两之间遗传类似度, 并据 此使用 UPGMA 聚类法得出图 3 所示的聚类树形图。

从图 3 可以看出 54 个单株具有明显的遗传聚 群特性, 可以大致分为 8 个小聚群, 即: 第 1 群为 2 、 $3 、 4 、 12 、 14$ 号单株; 第 2 群为 $5 、 6 、 7 、 9 、 10 、 11$; 第 3 群 为 $15 、 16 、 18 、 23 、 24 、 25 、 30$ 号单株; 第 4 群为 $19 、 20$ 、 $21 、 27 、 28$ 号单株; 第 5 群为 $22 、 26$ 号单株; 第 6 群为 $32 、 33 、 34 、 35 、 36 、 41 、 42 、 44 、 45 、 46$ 号单株; 第 7 群为 $37 、 38 、 39 、 40$ 号单株; 第 8 群为 $47 、 48 、 49 、 50 、 51 、 52$ 、 53 、54 号单株。如果我们把这些遗传类似程度较高 的小聚群看作一个邻域 ( Neighborhood)(周必成等, 2000 ), 那么可以得出珙桐邻域示意图 (图 4), 从图 4 可以推算出珙桐相邻区大小 ( Neighborhood size) (直 径) 为 $15 \sim 30 \mathrm{~m}$ 。平均为 $25 \mathrm{~m}$ 。

\section{4 群体遗传标记的捕获曲线}

捕获曲线是描述多项式相对数量增长与随机抽 样的群体或个体数量成比例的曲线, 用以根据试验 样本的群体内的最小数量遗传信息捕获总体的合理 遗传变异(顾万春等, 1998)。珙桐 13 个引物 101 个 位点的 RAPD 标记, 总的多态位点百分率为 $97.03 \%$ 。为确定最小具体抽样对总体遗体变异的捕 获量, 本研究以多态位点百分率为变量, 利用 POP-
GENE 软件对随机抽样群体数及群体内抽样个体数 进行计算, 得出捕获曲线图。根据图 5 建立的捕获 曲线可知, 随机抽样 3 个群体的多态位点百分率可 靠性可达 95\%，抽样 4 个群体的可靠性可达 $99 \%$ 。 群体内随机抽样 25 个个体的可靠性达 $95 \%$, 随机抽 样 30 个个体的可靠性可达 $99 \%$ 。

\section{5 取样数目对遗传学参数的影响}

适当的采样数目不仅可以节省大量的人力和物 力, 减少不必要的浪费, 而且可以提高分析问题的效 率。本研究从每个群体中, 按 $10 、 20 、 30$ 个个体 3 个 级分别进行随机抽样, 来代表该群体进行遗传学计 算, 每个级别随机重复抽样 10 次。用 POPGENE 进 行计算, 讨论不同的取样数目对遗传学参数的影响, 所得结果见图 6、图 7、图 8 和图 9。

由图 6 及图 7 可见,有效等位基因数 $(\mathrm{Ne})$ 和基 因多样度 $(h)$ 受取样个体数的影响很小, 即使在每 个群体只取 10 个样时, 也能较好地反映整个群体的 状况, 不过随着样本数的增大, 这种波动逐渐减小, 标准差逐渐减小, 当取样数达到 30 个时, 重复 10 次 的值基本聚成一个点。而群体间的分化系数 $G_{s t}$ 和 基因流 $N m$ 值的估算则明显受取样个体数的影响较 大。就 $G_{s t}$ 而言, 当每个群体的取样个体数为 10 个 样本时, $G_{s t}$ 值每次相差较大, 且均偏离实际值较远, 当每个群体取 20 个样本时, $G_{s t}$ 相差显著减小, 当样 


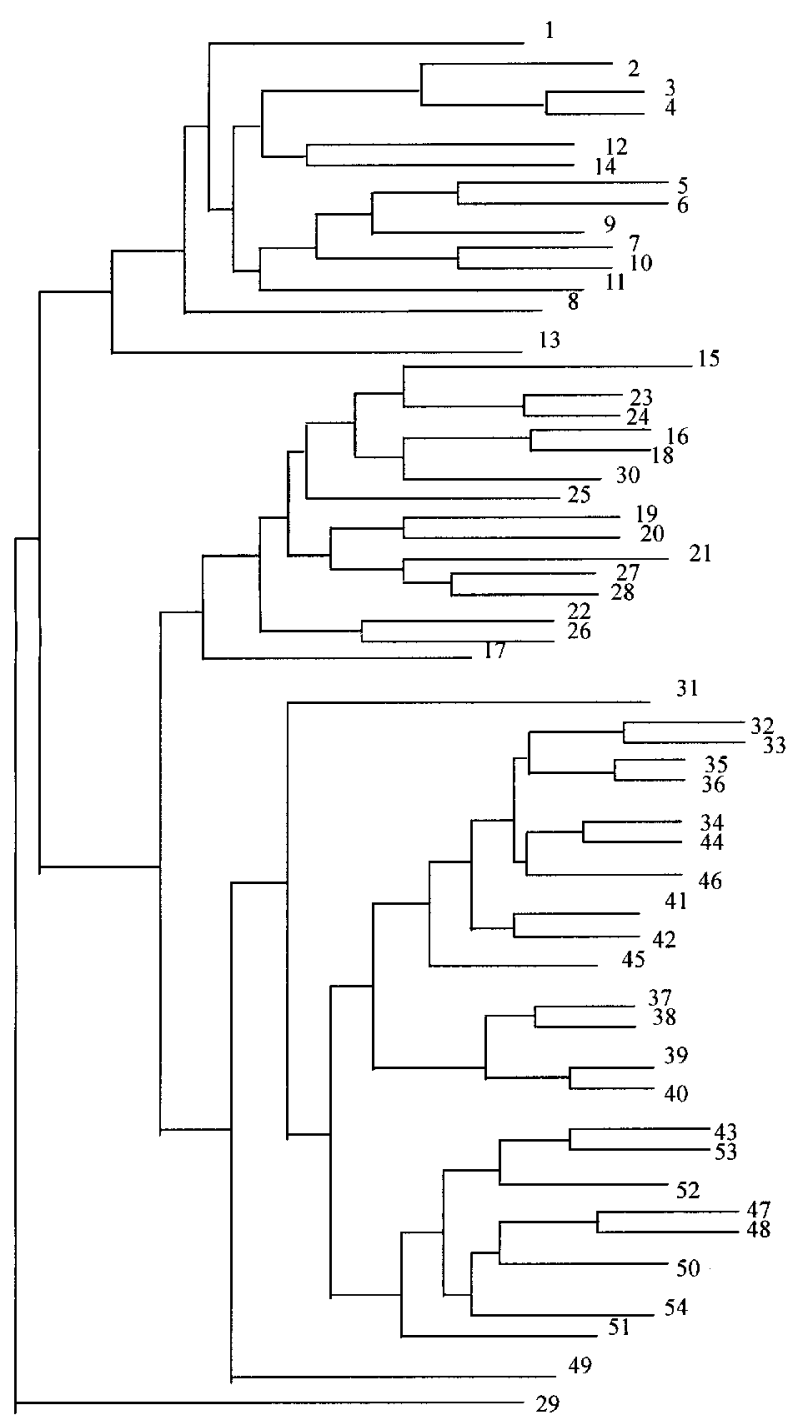

图 3 珙桐样地单株 UPGMA 聚类树状图

Fig. 3 UPGMA cluster dendrogram from individual plant in sample plot of Davidia involucrata

本数达 30 个时, $G_{s t}$ 基本上能代表整个群体的水平 （图 8）。对于基因流来说, 则随着抽取个体数的增 加, $N m$ 值逐渐增大 (图 9)。说明抽样样本数达 30 个时, 基本上能代表整个群体的遗传多样性水平。

\section{3 讨 论}

3.1 珙桐是我国特有的单种属植物, 起源古老, 其 濒危状况已被许多学者所公认。利用 RAPD 标记对 珙桐全分布区 5 个种群进行遗传多样性分析结果表 明, 珙桐虽因小种群效应和距离隔离效应经历了严 重的遗传漂变, 种群内仍具有丰富的遗传变异, 但是 遗传分化巨大, $26 \%$ 的遗传变异存在于种群间, 与我 国濒危树种马补木 (李建民等, 2002)、银杉 (汪小全 等, 1996)等相似, 而与广布性树种相异。造成这种
群体分化严重的原因可能包括以下几个方面: 首先, 从分布范围来看, 珙桐是一个特有种或狭域种。从 分布范围来看, 特有种在四种形式(特有种、狭域种、 地区种、广布种)的分布中, 其分化程度是最高的, 狭 域种仅次于特有种。这与我们的研究珙桐的遗传分 化得出的结论是相符合的。其次, 从生活型来看, 珙 桐为多年生乔木, 世代周期长; 而从交配系统这个最 主要的影响因子来看, 珙桐具有两性花或雌花常与 雄花同株, 是一个典型的自交物种, Bussell（1999） 曾对 35 个物种的 RAPD研究结果进行了总结, 发现

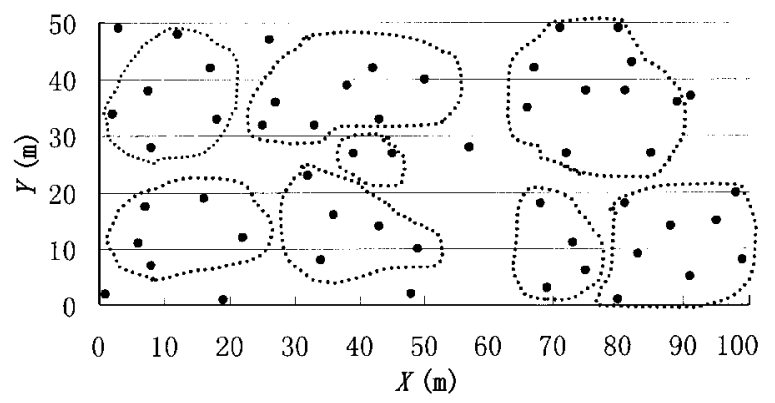

图 4 珙桐相邻域示意图

Fig.4 Diagrammatic sketch of neighboring region in Davidia involucrata
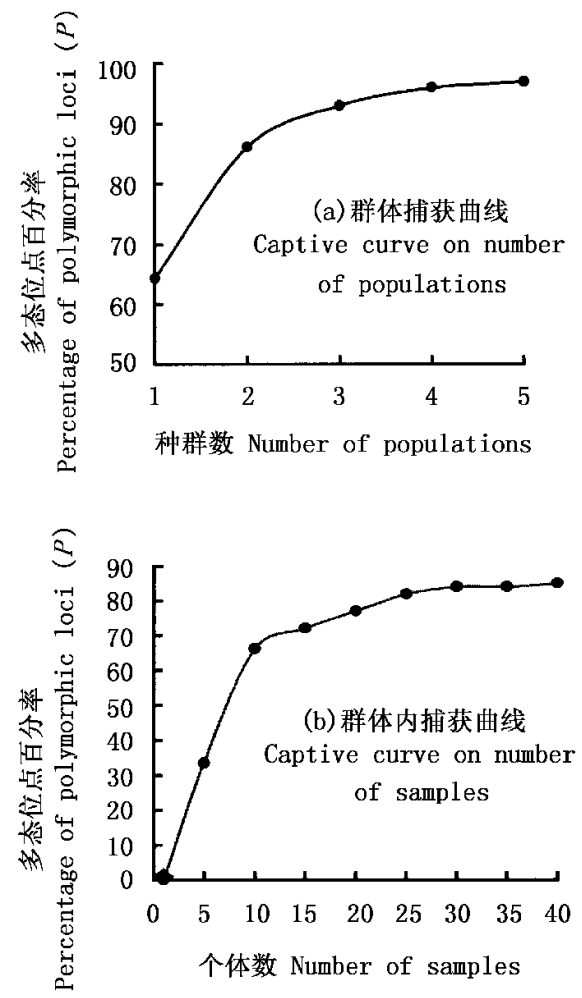

图 5 珙桐群体遗传标记捕获曲线

Fig.5 Captive curve on genetic mark of Davidia involucrata population 


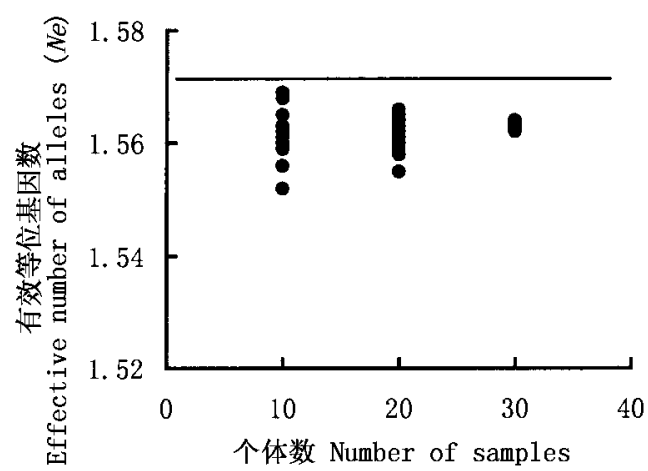

图 6 有效等位基因数和取样个体数之间的关系

Fig.6 The value of effective number of alleles $(\mathrm{Ne})$ obtained by the different number of samples individuals $(10 \times 10,20 \times 10,30 \times 10)$

图中水平线为根据全部采样个体所得到的数值, 每个小点为每 次抽样所得到的遗传参数值 (下同) The horizontal line is based on all the Davidia involucrata individuals and each dot is generated from each sampling, the same below

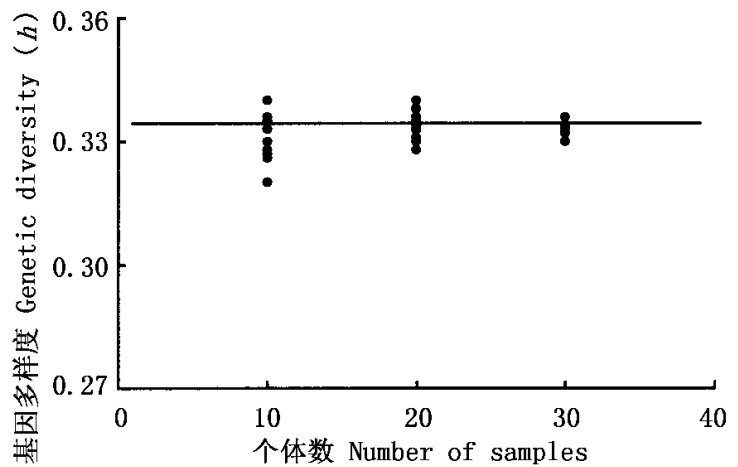

图 7 基因多样度和取样个体数之间的关系

Fig.7 The value of genetic diversity $(h)$ obtained by the different number of samples $(10 \times 10,20 \times 10,30 \times 10)$

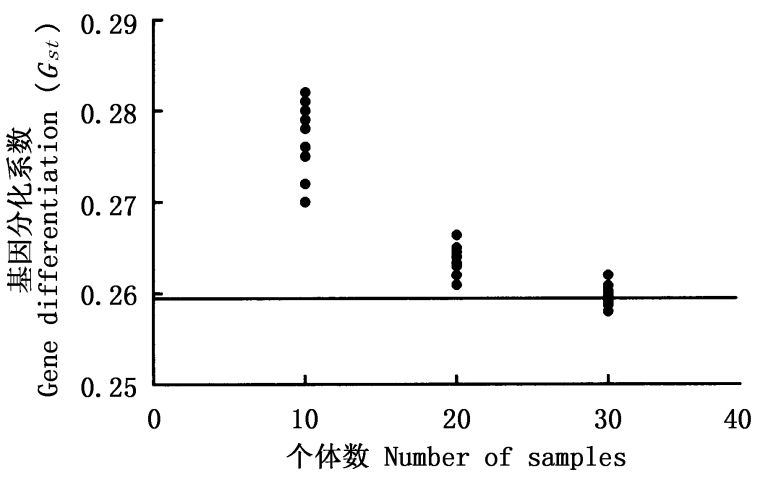

图 8 基因分化系数和取样个体数之间的关系

Fig. 8 The value of gene differentiation $\left(G_{s t}\right)$ obtained by the different number of samples $(10 \times 10,20 \times 10,30 \times 10)$

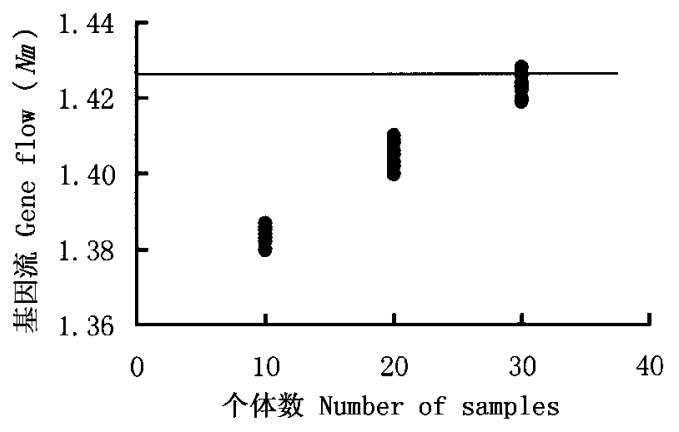

图 9 基因流和取样个体数之间的关系

Fig.9 The value of gene flow $(\mathrm{Nm})$ obtained by the different number of samples $(10 \times 10,20 \times 10,30 \times 10)$

29 个远交物种的群体间变异在总的遗传变异中平 均占 $19.3 \%\left(G_{s t}=0.193\right)$, 而 6 个近交物种的平均 $G_{s t}$ 值为 0.625 。此外, 从基因流水平来评价, 珙桐群 体间基因流是相当小的 (RAPD 标记所估测的 $\mathrm{Nm}$ 值分别为 1.4239 ), 植物的基因流主要是借助于花 粉、种子等遗传物质携带者的迁移或运动来实现的, 其中花粉和种子的扩散和传播是两种最主要的形式 （Hamrick 1987）。珙桐种子较大, 主要靠重力传播和 动物搬运, 而且, 珙桐种子后熟休眠期特别长, 发芽 率极低, 有“千花一果”之说, 诸多影响因素使珙桐群 体间的基因流动严重受阻, 与我们得出的珙桐群体 间基因流小是相一致的。

\section{2 珙桐种质资源保存的样本策略}

物种保护策略和措施的制定必须建立在对物种 多样性水平和群体遗传结构充分了解的基础上。对 一个遗传变异主要存在于群体之内的物种和一个遗 传变异主要分布于群体之间的物种应具有完全不同 的取样和保护方针。在实际取样时, 对于一个基因 流比较小, $G_{s t}$ 值为 0.60 的物种, 至少要取样 6 个群 体才能保存其 $95 \%$ 的遗传多样性; 而对 $G_{s t}$ 值为 0.20 的物种, 要达到同样的效果则只需取样 2 个群体就 足够 (葛颂等, 1997)。特别是高度特化的单型种的 研究和保护中, 我们必须充分重视物种的遗传多样 性和群体遗传结构。

开展森林树种种质资源保存，样本策略是保持 基因频率完整性的关键技术，也是以最少资金投入 达到最大限度保存森林树种及其种质资源的关键。 本研究通过对珙桐种质资源的遗传多样性及群体遗 传结构的研究, 提出其原地保存及异地保存的样本 策略: 
1）原地保存的样本策略由珙桐群体遗传标记 捕获曲线得知, 3 个群体的代表性为 $95 \%, 4$ 个 群体 的代表性为 $99 \%$; 群体内 25 个个体的代表性为 95\%,30个个体的代表性为 $99 \%$ 。由群体遗传距离 分析结果得知, 湖北神农架与贵州梵净山距离最近, 而遗传多样性的丰富度依次为贵州梵净山、湖北神 农架、四川峨眉山、甘肃文县和湖北宣恩, 据此确定 珙桐天然林原地保存抽样林分 (群体) 在贵州梵净 山、四川峨眉山和甘肃文县等 3 个,每林分(群体)保 存目的个体 30 个。由群体遗传结构分析结果得知 珙桐相邻区大小为 $15 \sim 30 \mathrm{~m}$, 据此确定株间最小间 距 $30 \mathrm{~m}$ 以上, 这样每个林分 (群体) 保存面积为 (30 株 $\times 30 \mathrm{~m} \times 30 \mathrm{~m}) 2.7 \mathrm{hm}^{2}$ 。因此珙桐原地保存的样 本策略为: 选择甘肃文县、四川峨眉山、贵州梵净山 3 个种群作为保存对象, 每个群体保存面积 $3 \mathrm{hm}^{2}$ 以 上。

2）异地保存的样本策略在异地保存中, 要尽可 能保存基因的多样度,因此其样本策略应为: 抽取甘 肃文县、四川峨眉山、湖北神农架、贵州梵净山 4 个 群体, 每个群体抽样 30 个个体, 每个个体的株间最 小间距 $30 \mathrm{~m}$ 以上, 总计保存 150 个 $(>4 \times 30)$ 个体, 分别在东南部和西北部建立一个异地保存点。

\section{参 考 文 献}

Bussell JD (1999). The distribution of RAPD diversity amongst population of Isotoma petraea (Lobeliaceae) . Molecular Ecology, 8, $775-789$.

Doyle JJ, Doyle JL (1987) . A rapid DNA isolation procedure for small quantities of fresh leaf tissue. Phytochemistry Bulleth, 19, $11-15$.

Fu LG (傅立国) (1992). Chinese Red Book - Rare Plant (First Volume) (中国植物红皮书(第一册)). Science Press, Beijing. (in Chinese)
Ge S (葛颂)，Wang HQ (王海群), Zhang CM (张灿明), Hong DY (洪德元) (1997). Genetic diversity and population differentiation of Cathaya argyrophylla in Bamian Mountain. Acta Botanica Sinica (植物学报), 39, 266-271. (in Chinese with English abstract)

Gu WC (顾万春), Wang Q (王棋), You YT (游应天) (1998). Outline of Forestry Hereditary Resource (森林遗传资源学概 论). Chinese Science and Technology Press, Beijing. (in Chinese)

Hamrick JL (1987) . Gene flow, distribution of genetic variation in plant populations. In: Urbanska K ed. Differentiation Patterns in Higher Plants. Academic Press, New York, 53-67.

Li JM (李建民), Zhou ZC (周志春), Wu KY (吴开云), Jin GQ (金国庆) (2002). Genetic differentiation of geographic populations in Liriodendron chinense using RAPD markers. Scientia Silvae Sinicae (林业科学), 38(4), 60-66. (in Chinese with English abstract)

Nei M (1978). Estimation of average heterozygosity and genetic distance from a small number of individuals. Genetics, 89, 583 -590 .

Wang XQ (汪小全), Zou YP (邹喻苹), Zhang DM (张大明) (1996) . Analysis on genetic diversity of Cathaya argyrophylla by RAPD. Science in China Series $C$ (中国科学 C 辑) , 26, 436441. (in Chinese with English abstract)

Yeh FC, Yang RC (1997). POPGENE V 1.31. download from http://www. ualberta.ca/ fyeh/

Zhang QH (张清华), Guo QS (郭泉水), Xu DY (徐德应), Yan H (阎洪) (2000). Influence of climate changes on geographical distribution of Davidia involucrata, the precious and endangered species native to China. Scientia Silvae Sinicae (林 业科学), 36(2), 47-52. (in Chinese with English abstract)

Zhou BC (周必成), Song CW (宋丛文) Rong HM (荣花茂) (2000). Analysis on genetic structure of natural Pinus massoniana forest from Xiaochang using isozyme. Hubei Forestry Science and Technology (湖北林业科技), Suppl, 53-60. (in Chinese with English abstract) 